\section{Risk stratification in laminopathies and Emery Dreifuss muscular dystrophy}

\author{
Abdallah Fayssoil \\ CHU Raymond Poincaré et Université \\ Versailles Saint Quentin en Yvelines, \\ Garches, France
}

\begin{abstract}
Laminopathies are genetic disorders due to gene mutation encoding for proteins of the nuclear envelope. Patients are at risk of conduction defect, arrhythmia, sudden death and heart failure. The authors summarize predictive factors for cardiac events reported in the literature in this group of disease.
\end{abstract}

\section{Introduction}

Laminopathies are genetic disorders due to gene mutation encoding for proteins of the nuclear envelope that include emerin and lamins. Emery Dreifuss muscular dystrophy (EDMD) is a neuromuscular disorder, reported in 1966 by Emery and Dreifuss, ${ }^{1}$ characterized by peripheral skeletal muscular weakness, joint contractures and cardiac conduction disorders. ${ }^{2}$ Clinical spectrum is large in laminopathy, ranging from skeletal muscle failure to heart disease. Heart involvement is crucial to search since cardiolaminopathy affects prognosis, due to risk of conduction defect, ventricular arrhythmia and heart failure. Predictive factors for significant cardiac events are essential to know in clinical practice.

\section{Laminopathies}

Laminopathies are due to LMNA mutations, leading to a wide spectrum of diseases that may include dilated cardiomyopathy with conduction defect, ${ }^{3}$ neuropathy, limb girdle muscular dystrophy type IB (LGMD1B), ${ }^{4}$ congenial form of muscular dystrophy, 5 EDMD, lipodystrophy type Dunnigan, mandibulo-acral dysplasia and Hutchinson-Gilford progeria syndrome.

LMNA gene is located on chromosome 1q21 and encodes lamins $\mathrm{A}$ and $\mathrm{C}$ that are A-type lamins. Lamines $\mathrm{A}$ and $\mathrm{C}$ are nuclear intermediate filaments proteins, forming a meshwork (the nuclear lamina) within the inner nuclear membrane. Lamines A and C provide a mechanical stabilization of the nucleus and act as a scaffold for nuclear factors. In 1999, Bonne et al. ${ }^{6}$ reported the first LMNA mutation gene in a group of patients with autosomal dominant EDMD. LMNA mutation was found to be present in $8 \%$ of patients with dilated cardiomyopathy. A subset of clinical parameters has been shown to be predictive for LMNA mutations in dilated cardiomyopathy: supraventricular arrhythmia, conduction defects, presence of skeletal muscle failure and moderate cardiomyopathy.

In patients with lamins $\mathrm{A} / \mathrm{C}$ mutation, cardiac involvement may include atrio-ventricular conduction and sinus node disorders. Conduction system disease seems to appear earlier, reaching $18 \%$ in patients $<10$ years whereas cardiomyopathy seems to occur later, reaching $60 \%$ in older patients (>50 years). ${ }^{7}$ Other cardiac phenotypes have been reported to be associated with LMNA mutations. $4 \%$ of patients with arythmogenic right ventricular cardiomyopathy and without desmosomal gene mutations carried LMNA mutations. ${ }^{8}$ Apical left ventricular aneurysm associated with ventricular rhythm impairment has been reported in two members of family carrying LMNA mutations. 9 In a recent study, LMNA, TTN and MYBPC3 genes were found to be the most prevalent genes disease associated with left ventricular noncompaction. ${ }^{10}$

\section{Emery Dreifuss muscular dystrophy}

Emery Dreifuss muscular dystrophy is the most known muscular dystrophy among laminopathies. We distinguish:

i. An X linked form related to mutation in EMD gene. In 1994, Bione et al. ${ }^{11}$ identified the gene. The EMD gene is located on chromosome Xq28 and encodes emerin, a protein of the inner nuclear membrane. Emerin is involved in gene expression regulation, chromatin architecture and cell signaling.

ii. Au autosomal dominant form related to mutation in LMNA gene 6

iii. An autosomal recessive form which seems to be rare ${ }^{12}$

iv. Recently, FHL1 dysregulation has been reported to be associated with EDMD 13 Heart involvement includes arrhythmia, conduction defects and dilated cardiomyopathy. Heart disease is characterized by progressive replacement of myocardium by adipose and fibrosis tissue that begins in atria and affects progressively atrio-ventricular node and ventricles. Symptoms may occur early, with conduction defects and cardiac disease become usual in the third
Correspondence: Abdallah Fayssoil, Raymond Poincaré Hospital, APHP, 104 Boulevard Raymond Poincaré, 92380 Garches, France. E-mail: fayssoil2000@yahoo.fr

Key words: LMNA, emerin, laminopathy, arrhythmia, sudden death.

Contributions: the authors contributed equally.

Conflict of interest: the authors declare no potential conflict of interest.

Funding: none.

Received for publication: 26 October 2017.

Revision received: 28 November 2017.

Accepted for publication: 2 December 2017.

This work is licensed under a Creative Commons Attribution NonCommercial 4.0 License (CC BY-NC 4.0).

CC Copyright A. Fayssoil, 2018

Licensee PAGEPress, Italy

Neurology International 2018; 10:7468

doi:10.4081/ni.2018.7468

decade. Bradycardia, complete atrio-ventricular block, atrial paralysis can occur in EDMD as well as supraventricular and ventricular arrhythmia. ${ }^{7}$ Sudden cardiac death (SCD) may be the initial manifestation of disease. 14

\section{Risk stratification}

Patients with EDMD and laminopathies are at risk of SCD. Ventricular arrhythmia and sudden death may occur despite pacemaker implantation. ${ }^{7}$ The risk for ventricular arrhythmia was reported to reach $18 \%$ in a study that included 269 LMNA mutation carriers (median follow up 43 months). ${ }^{15}$ In a study that included 122 LMNA mutation carriers (follow up 7 years), the cumulative atrio-ventricular (AV) block events were $57 \pm 5 \%$, atrial arrhythmia $63 \pm 5 \%$ and ventricular arrhythmia $34 \pm 5 \% .{ }^{16}$ In the study by Meune et al.,17 $42 \%$ of patients with LMNA mutation carrying an implantable cardioverter-defibrillator (ICD) received appropriate shock in relation with arrhythmia. Prophylactic implantation of an implantable cardioverter defibrillator (ICD) need to be considered and discussed in LMNA mutations patient's with conduction system disorders.

Some parameters merged from the literature for risk stratification. In the study by Pasotti et al., 18 the following parameters were found to be predictive factors for heart failure or death: NYHA III or IV, conduc- 
tion system disorder, clinical manifestation of LMNA deficiency, left ventricular ejection fraction (LVEF) $<35 \%$, left ventricular end diastolic volume $>180 \mathrm{~mL}$ and history of competitive sport. In multivariate analysis, NYHA III or IV and history of competitive sport were predictive factors for congestive heart failure or SCD or death. ${ }^{18}$ In the study by Van Rijsingen et al., 15 risk factors for ventricular arrhythmia were: male gender, non-sustained ventricular tachycardia, $\mathrm{LVEF}<45 \%$ and non-missense mutation. Recently, Kumar et al. 16 reported the following parameters as predictive factors for cardiac events: male gender, $\mathrm{LVEF} \leq 50 \%$ and non-missense mutations.

\section{Conclusions}

Patients with EDMD and laminopathies are at risk for cardiac morbidity ad mortality due to rhythmic events and dilated cardiomyopathy. Risk stratification relies on genetic, electrocardiogram (EKG), EKG Holter findings as well as LVEF value and exercise testing. Cardiac magnetic resonance imaging and electrophysiological studies may provide additional prognostic value and require more future research in this field.

\section{References}

1. Emery AE, Dreifuss FE. Unusual type of benign $\mathrm{x}$-linked muscular dystrophy. J Neurol Neurosurg Psychiatry 1966;29:338-42

2. Ellis JA. Emery-Dreifuss muscular dystrophy at the nuclear envelope: 10 years on. Cell Mol Life Sci 2006;63:2702-9

3. Fatkin D, MacRae C, Sasaki T, et al. Missense mutations in the rod domain of the lamin $\mathrm{A} / \mathrm{C}$ gene as causes of dilated cardiomyopathy and conduction-system disease. N Engl J Med 1999;341:1715-24.

4. Muchir A, Bonne G, van der Kooi AJ, et al. Identification of mutations in the gene encoding lamins $\mathrm{A} / \mathrm{C}$ in autosomal dominant limb girdle muscular dystrophy with atrioventricular conduction disturbances (LGMD1B). Hum Mo Genet 2000;9:1453-9.

5. Quijano-Roy S, Mbieleu B, Bönnemann CG, et al. De novo LMNA mutations cause a new form of congenital muscular dystrophy. Ann Neurol 2008;64:177-86.

6. Bonne G, Di Barletta MR, Varnous S, et al. Mutations in the gene encoding lamin $\mathrm{A} / \mathrm{C}$ cause autosomal dominant Emery-Dreifuss muscular dystrophy. Nat Genet 1999;21:285-8.

7. van Berlo JH, de Voogt WG, van der Kooi AJ, et al. Meta-analysis of clinical characteristics of 299 carriers of LMNA gene mutations: do lamin $\mathrm{A} / \mathrm{C}$ mutations portend a high risk of sudden death? J Mol Med (Berl) 2005;83:7983.

8. Quarta G, Syrris P, Ashworth M, et al. Mutations in the Lamin $\mathrm{A} / \mathrm{C}$ gene mimic arrhythmogenic right ventricular cardiomyopathy. Eur Heart J 2012;33: 1128-36.

9. Forissier JF, Bonne G, Bouchier C, et al. Apical left ventricular aneurysm without atrio-ventricular block due to a lamin $\mathrm{A} / \mathrm{C}$ gene mutation. Eur J Heart Fail 2003;5:821-5.

10. Sedaghat-Hamedani F, Haas J, Zhu Fet al. Clinical genetics and outcome of lef ventricular non-compaction cardiomyopathy. Eur Heart J 2017 Oct 6.

11. Bione S, Maestrini E, Rivella S, et al. Identification of a novel X-linked gene responsible for EmeryDreifuss muscular dystrophy. Nat Genet 1994;8:323-7.

12. Di Barletta RM, Ricci E, Galluzzi G, et al. Different mutations in the LMNA gene cause autosomal dominant and autosomal recessive Emery-Dreifuss muscular dystrophy. Am J Hum Genet 2000;66:1407-12.

13. Tiffin HR, Jenkins ZA, Gray MJ, et al. Dysregulation of FHL1 spliceforms due to an indel mutation produces an Emery-Dreifuss muscular dystrophy plus phenotype. Neurogenetics 2013; 14:113-21

14. Finsterer J, Stöllberger C, Maeztu C. Sudden cardiac death in neuromuscular disorders. Int J Cardiol 2016;203:50815.

15. van Rijsingen IA, Arbustini E, Elliott PM, et al. Risk factors for malignant ventricular arrhythmias in lamin a/c mutation carriers a European cohort study. J Am Coll Cardiol 2012;59:493500.

16. Kumar S, Baldinger SH, Gandjbakhch E, et al. Long-Term Arrhythmic and Nonarrhythmic Outcomes of Lamin A/C Mutation Carriers. J Am Coll Cardiol 2016;68:2299-307.

17. Meune C, Van Berlo JH, Anselme F, et al. Primary prevention of sudden death in patients with lamin $\mathrm{A} / \mathrm{C}$ gene mutations. N Engl J Med 2006;354:209-10.

18. Pasotti M, Klersy C, Pilotto A, et al. Long-term outcome and risk stratification in dilated cardiolaminopathies. J Am Coll Cardiol 2008;52:1250-60. 